\title{
Prevalence of dyslipidemia and its association with insomnia in a community based population in China
}

Yiqiang Zhan ${ }^{1,2+}$, Fen Zhang ${ }^{3}$, Leihong $\mathrm{Lu}^{4+}$, Jinsong Wang ${ }^{5}$, Yihong Sun ${ }^{6}$, Rongjing Ding ${ }^{6}$, Dayi Hu ${ }^{6}$ and Jinming $\mathrm{Yu}^{1,2^{*}}$

\begin{abstract}
Background: Studies of the prevalence of dyslipidemia and its association with insomnia are scarce in China. This study investigated the prevalence of dyslipidemia and its association with insomnia in a community based Chinese population.

Methods: We conducted a cross-sectional survey in Beijing and recruited 10054 participants aged $\geq 18$ years. The association between self-reported insomnia and dyslipidemia was determined by multiple logistic regression models. Age, gender, education, obesity, body mass index, physical activity, current smoking, current drinking, diabetes, and hypertension were adjusted as confounders. Odds ratios (ORs) with corresponding 95\% confidence intervals (Cls) were reported as effect measurements.

Results: The prevalence of dyslipidemia in those with no insomnia, occasional insomnia, and frequent insomnia were $53.3 \%, 54.3 \%$, and $54.5 \%$ in men and 52.0\%, 54.8\%, and $61.2 \%$ in women. Compared with subjects with no insomnia, the multivariate adjusted ORs and $95 \%$ Cls for those with occasional insomnia and frequent insomnia were $1.07(0.86 \sim 1.34)$ and $1.19(0.89 \sim 1.60)$ for men, and 1.00(0.86 1.14) and 1.23(1.03 1.47) for women.
\end{abstract}

Conclusions: These observations indicate that frequent insomnia was associated with a higher prevalence of dyslipidemia in women. This association was not significant in men.

Keywords: Insomnia, Dyslipidemia, Total cholesterol, Chinese population, Cross-sectional study

\section{Background}

Dyslipidemia is one of the most import and modifiable risk factors for atherosclerosis [1], stroke [2], and cardiovascular diseases [3]. Previous studies reported that the prevalence of dyslipidemia in China was lower than that in Western countries in the year around 2000 [4-9]. Nevertheless, China has been developing so rapidly during the last decades. The fast economic growth and social change are accompanied by transformation of daily lifestyle of the ordinary people. The prevalence of dyslipidemia might also have been changed and different from

\footnotetext{
* Correspondence: jmy@fudan.edu.cn

${ }^{\dagger}$ Equal contributors

'Key Laboratory of Public Health Safety, Ministry of Education, School of

Public Health, Fudan University, Shanghai, P. R. China

${ }^{2}$ Institute of Clinical Epidemiology, School of Public Health, Fudan University, Shanghai, P. R. China

Full list of author information is available at the end of the article
}

those in the previous reports. Thus, an update of our knowledge regarding the prevalence of dyslipidemia is largely on the agenda.

Studies suggested that sleep deprivation might be associated with dyslipidemia [10-12]. But few of them examined the association between insomnia and dyslipidemia in a population based survey. Insomnia is a subjective feeling of having difficulty initiating, maintaining or restoring sleep, or having poor sleep quality [13]. It was reported to be associated with substantial impairments of an individual's quality of life [14], depression [15], and accident occurrence [16]. Although recent studies have showed that insomnia was associated with higher risks of cardiovascular diseases $[17,18]$, more research is needed to clarify its relationship with dyslipidemia. The primary objective of the present study as a priori was to test whether insomnia was associated with higher 
prevalence of taking into account of several established risk factors of dyslipidemia based on a community-based survey in a Chinese population.

\section{Methods Study design}

This survey was a cross-sectional study regarding chronic diseases and risk factors conducted in Beijing in 2007 [19]. Citizens or permanent residents $\geq 18$ years old were enrolled by a multistage stratified random sampling design. According to local economic development level, two urban districts, one urban-rural mixed district, and one rural district were selected, and then 38 communities (17 urban communities and 21 rural communities) were randomly sampled. Before collecting the data, we informed local administrators of the aim and method of our survey. With their help, we could convey information of our study design via broadcasting and booklets. At the night before our survey, the participants were told not to drink or eat from $8 \mathrm{pm}$ to 8 am the next day. Written informed consents were obtained from all study participants, and the ethical approval was obtained from the Ethic Committee of Beijing Municipal Science and Technology Commission.

\section{Sample}

In total, we intended to recruit around 300 participants in each study community. Finally, 12041 participants were invited, and 10054 participants were recruited with a response rate of $83.5 \%$. Of them, $3687(36.7 \%)$ were men and 6367(63.3\%) were women. The age of men in our sample ranged from 20 to 96 years with a median age being 53 years. Likewise, the age of women in this sample ranged from 20 to 91 years with a median age being 53 years.

\section{Data collection}

The health interview was performed by trained medical staff at community health centers using a well-established and validated questionnaire to collect demographic and behavioral characteristics of the study population. Demographic information included birthday, gender, and education. Behavioral information included current smoking status, current drinking status, and physical activities. Education level was categorized as elementary school or lower ( $<7$ years), middle or high school ( $7 \sim 12$ years), and college or higher ( $>12$ years).

Physical examination included anthropometric measurements, blood pressure, medical history, and drug administration history. Height and weight were measured to the nearest $0.1 \mathrm{~cm}$ and $0.1 \mathrm{~kg}$ respectively with the subject standing barefoot in light clothes. Waist circumference was measured to the nearest $0.1 \mathrm{~cm}$ at the midpoint between the 12th rib and right anterior superior iliac spine. Body mass index (BMI) was calculated as weight $(\mathrm{kg})$ to be divided by square of height $(\mathrm{m})$. Blood pressure was measured using standard mercury sphygmomanometer on the right arm in sitting position after the participants rested for 5 minutes. Phase 1 and phase 5 Korotkoff sound was used as systolic blood pressure (SBP) and diastolic blood pressure (DBP) respectively. Blood pressure was measured twice with the average results for the present data analysis. Medical history and drug administration history were obtained from medical records and confirmed by community general practitioners. All the measurements were adopted by community licensed physicians.

Blood samples were collected from all the participants after an overnight fasting. All the biochemical assessments were conducted in the central laboratory of Peking University People's Hospital. Concentrations of fasting glucose, total cholesterol (TC), high-density lipoprotein cholesterol (HDL-C), triglycerides (TG), and low-density lipoprotein cholesterol (LDL-C) were measured using an auto analyzer (Hitachi 717, Hitachi Instruments Inc., Tokyo, Japan). Diabetes mellitus was defined as fasting glucose $\geq 7.0 \mathrm{mmol} / \mathrm{L}$ or current medication for diabetes [20]. Hypertension was defined as SBP $\geq 140 \mathrm{mmHg}$, DBP $\geq 90 \mathrm{mmHg}$, or current medication for hypertension [21]. Obesity was defined as waist circumstances $>90 \mathrm{~cm}$ in men and $>85 \mathrm{~cm}$ in women.

\section{Determination of self-reported insomnia and dyslipidemia} Self-reported insomnia was collected via a question: "During the last month, have you had insomnia (e.g.: difficulty falling asleep or non-restorative sleep)?" with the following response options: no insomnia, occasional insomnia (1-2 times/week), and frequent insomnia ( $\geq 3$ times/week). Abnormal TC was defined as TC $>5.18$ $\mathrm{mmol} / \mathrm{L}$, abnormal TG was defined as TG $>1.70 \mathrm{mmol} / \mathrm{L}$, abnormal LDL-C was defined as LDL-C $>3.37 \mathrm{mmol} / \mathrm{L}$, and abnormal HDL-C was defined as HDL-C $<1.04$ $\mathrm{mmol} / \mathrm{L}$. Dyslipidemia was defined as any of the followings being abnormal: TC, TG, LDL-C, or HDL-C according to Chinese Guidelines on Prevention and Treatment of Dyslipidemia in Adults [22].

\section{Statistical analysis}

Continuous variables were presented as mean \pm standard deviation $(\mathrm{SD})$ and categorical variables were presented as frequencies and proportions. In the descriptive analysis, we present the basic characteristics of study subjects and the prevalence of dyslipidemia and its individual components by insomnia. Cochran-Armitage method [23], which was developed for linear trends test in proportions or frequencies, was used for trend test in the associations between insomnia status (no insomnia, occasional insomnia, and frequent insomnia) and lipid 
status. Then in the exploratory analysis, we examined the association between insomnia and dyslipidemia using multiple logistic regression models in both men and women altogether. We also examined the interaction terms and found that there was an interaction effect between gender and insomnia for dyslipidemia. Then we examined the association in men and women separately. Three models were used for the analysis. The first model only included insomnia followed by the second model adjusted for age (plus gender for both genders together) as confounders. The third model was further adjusted for BMI, education, current smoking, current drinking, physical activity, obesity, diabetes, and hypertension as confounders. Odds ratios (ORs) with 95\% confidence intervals $(\mathrm{CIs})$ were presented, and $P<0.05$ was considered to be statistically significant. All of the statistical analyses were conducted using R 2.15 [24].

\section{Results}

\section{Basic characteristics of study subjects}

Table 1 demonstrates the basic characteristics of study participants by gender and insomnia status. In total, the

Table 1 Basic characteristics of the study subjects

\begin{tabular}{|c|c|c|c|c|c|c|}
\hline & \multicolumn{3}{|c|}{ Men } & \multicolumn{3}{|c|}{ Women } \\
\hline & $\begin{array}{c}\text { No insomnia } \\
(n=3065)\end{array}$ & $\begin{array}{l}\text { Occasional insomnia } \\
(n=400)\end{array}$ & $\begin{array}{l}\text { Frequent insomnia } \\
(n=222)\end{array}$ & $\begin{array}{c}\text { No insomnia } \\
(n=4567)\end{array}$ & $\begin{array}{l}\text { Occasional insomnia } \\
(n=1145)\end{array}$ & $\begin{array}{c}\text { Frequent insomnia } \\
(n=655)\end{array}$ \\
\hline Age(years) & $52.4 \pm 13.6$ & $52.7 \pm 12.9$ & $56.4 \pm 13.7$ & $51.4 \pm 13.2$ & $54.4 \pm 12.4$ & $56.5 \pm 11.8$ \\
\hline $\mathrm{BMI}\left(\mathrm{kg} / \mathrm{m}^{2}\right)$ & $25.1 \pm 3.7$ & $24.9 \pm 3.7$ & $24.5 \pm 3.5$ & $25.6 \pm 4.1$ & $25.4 \pm 4.1$ & $25.2 \pm 3.9$ \\
\hline $\mathrm{TC}(\mathrm{mmol} / \mathrm{L})$ & $4.71 \pm 0.91$ & $4.70 \pm 0.92$ & $4.73 \pm 1.08$ & $4.89 \pm 0.98$ & $4.98 \pm 1.02$ & $5.08 \pm 1.00$ \\
\hline $\mathrm{TG}(\mathrm{mmol} / \mathrm{L})$ & $1.64 \pm 1.77$ & $1.62 \pm 1.65$ & $1.47 \pm 1.23$ & $1.45 \pm 1.24$ & $1.48 \pm 1.28$ & $1.49 \pm 1.11$ \\
\hline $\mathrm{LDL}-\mathrm{C}(\mathrm{mmol} / \mathrm{L})$ & $2.44 \pm 0.67$ & $2.43 \pm 0.64$ & $2.44 \pm 0.70$ & $2.54 \pm 0.70$ & $2.57 \pm 0.71$ & $2.62 \pm 0.67$ \\
\hline $\mathrm{HDL}-\mathrm{C}(\mathrm{mmol} / \mathrm{L})$ & $1.27 \pm 0.40$ & $1.24 \pm 0.28$ & $1.26 \pm 0.32$ & $1.36 \pm 0.29$ & $1.37 \pm 0.30$ & $1.38 \pm 0.32$ \\
\hline \multicolumn{7}{|l|}{ Education, n(\%) } \\
\hline $0 \sim 6$ years & $663(21.6)$ & $85(21.3)$ & $62(27.9)$ & 1398(30.6) & $425(37.1)$ & 291(44.4) \\
\hline $7 \sim 12$ years & $2000(65.3)$ & $256(64.0)$ & 133(59.9) & 2698(59.1) & $625(54.6)$ & $312(47.6)$ \\
\hline$>12$ years & $402(13.1)$ & $59(14.8)$ & $27(12.2)$ & $471(10.3)$ & $95(8.3)$ & $52(7.9)$ \\
\hline \multicolumn{7}{|c|}{ Physical Activity, n(\%) } \\
\hline No & 1467(47.9) & $206(51.5)$ & $104(46.8)$ & 2048(44.9) & 495(43.3) & $274(41.8)$ \\
\hline Yes & 1598(52.1) & 194(48.5) & $118(53.2)$ & $2516(55.1)$ & $649(56.7)$ & $381(58.2)$ \\
\hline \multicolumn{7}{|c|}{ Current Smoking, n(\%) } \\
\hline No & $829(27.0)$ & 109(27.3) & $49(22.1)$ & $4186(91.7)$ & 1028(89.9) & $565(86.3)$ \\
\hline Yes & $2236(73.0)$ & $291(72.7)$ & 173(77.9) & $381(8.3)$ & $116(10.1)$ & $90(13.7)$ \\
\hline \multicolumn{7}{|c|}{ Current Drinking, n(\%) } \\
\hline No & $1504(49.1)$ & 207(51.8) & 113(50.9) & $4351(95.3)$ & 1088(95.0) & $622(95.0)$ \\
\hline Yes & $1561(50.9)$ & 193(48.2) & 109(49.1) & 215(4.7) & $57(5.0)$ & $33(5.0)$ \\
\hline \multicolumn{7}{|l|}{ Obesity, n(\%) } \\
\hline No & $1672(54.6)$ & $221(55.3)$ & 135(60.8) & $2365(51.8)$ & $585(51.1)$ & $333(50.8)$ \\
\hline Yes & 1393(45.4) & $179(44.7)$ & $87(39.2)$ & $2202(48.2)$ & $560(48.9)$ & $322(49.2)$ \\
\hline \multicolumn{7}{|l|}{ Work stress, n(\%) } \\
\hline Low & $391(12.8)$ & $47(11.8)$ & $31(14.0)$ & $591(12.9)$ & 119(10.4) & $61(9.3)$ \\
\hline Intermediate & 1695(55.3) & $190(47.5)$ & $84(37.8)$ & $2547(55.8)$ & $574(50.2)$ & 291(44.6) \\
\hline High & $978(31.9)$ & $163(40.8)$ & $107(48.2)$ & $1428(31.3)$ & $451(39.4)$ & $301(46.1)$ \\
\hline \multicolumn{7}{|l|}{ Diabetes, n(\%) } \\
\hline No & 2719(88.7) & $351(87.7)$ & 199(89.6) & 4077(89.3) & 1004(87.7) & $567(86.6)$ \\
\hline Yes & $346(11.3)$ & $49(12.3)$ & $23(10.4)$ & 490(10.7) & $141(12.3)$ & $88(13.4)$ \\
\hline \multicolumn{7}{|l|}{ Hypertension, n(\%) } \\
\hline No & $1824(59.5)$ & $240(60.0)$ & 130(58.6) & $2957(64.7)$ & $641(56.0)$ & $326(49.8)$ \\
\hline Yes & $1240(40.5)$ & $160(40.0)$ & $92(41.4)$ & $1610(35.3)$ & $504(44.0)$ & $329(50.2)$ \\
\hline
\end{tabular}


numbers of men with no insomnia, occasional insomnia, and frequent insomnia were 3065(83.1\%), 400(10.8\%), and $222(6.1 \%)$, respectively, and those of women were $4567(71.7 \%), 1145(18.0 \%)$, and 655(10.3\%). The average ages of the subjects with no insomnia, occasional insomnia, and frequent insomnia were $52.4 \pm 13.6,52.7 \pm 12.9$, and $56.4 \pm 13.7$ years for men, while those for women were $51.4 \pm 13.2,54.4 \pm 12.4$, and $56.5 \pm 11.8$ years, respectively. Of the 10054 participants, 5374(53.5\%) were found with dyslipidemia. The concentrations of TC, TG, LDL-C, and HDL-C among different insomnia status were plotted in Figure 1 for men and Figure 2 for women.

\section{Prevalence of abnormal lipid profile}

As shown in Table 2, the prevalence of dyslipidemia for those with no insomnia, occasional insomnia, and frequent insomnia were $53.3 \%, 54.3 \%$, and $54.5 \%$ in men and $52.0 \%, 54.8 \%$, and $61.2 \%$ in women. The CochranArmitage trend test for the prevalence of dyslipidemia across different insomnia status was $P<0.0001$ for all participants. These trend tests were not consistent in men $(P=0.6313)$ and women $(P<0.0001)$.

\section{Association of insomnia and abnormal lipid profile}

Table 3 presents the association of serum lipid markers (TC, TG, LDL-C, and HDL-C) and insomnia. All of these models included age, BMI, education, physical activity, current smoking, current drinking, obesity, diabetes, and hypertension plus gender when men and women were analyzed together. ORs ( $95 \% \mathrm{CI})$ of TC for those with occasional insomnia, frequent insomnia were $1.00(0.79 \sim 1.27)$ and $1.15(0.85 \sim 1.57)$ compared with those with no insomnia in men. As for women, the ORs $(95 \% \mathrm{CI})$ of TC were 1.04(0.91 1.20) and 1.24(1.05 1.49) for the participants with occasional insomnia and frequent insomnia. In terms of TG, LDL-C, and HDL-C, their associations with insomnia were not statistically significant. Additional analysis was made when treating serum lipids as continuous variables corresponding to Figures 1 and 2 by gender. We only observed significant results for TC in women $(P<0.001)$.

\section{Association of insomnia and dyslipidemia}

The association of insomnia and dyslipidemia were described in Table 4. Model 1 included only insomnia, model 2 was adjusted for age (plus gender when men and women were analyzed together), and model 3 was further adjusted for several other confounders (BMI, education, physical activity, current smoking, current drinking, obesity, diabetes, and hypertension). Compared with those without insomnia, the corresponding ORs and $95 \% \mathrm{CI}$ for subjects with occasional insomnia and frequent insomnia were $1.07(0.86,1.34)$ and $1.19(0.89$,






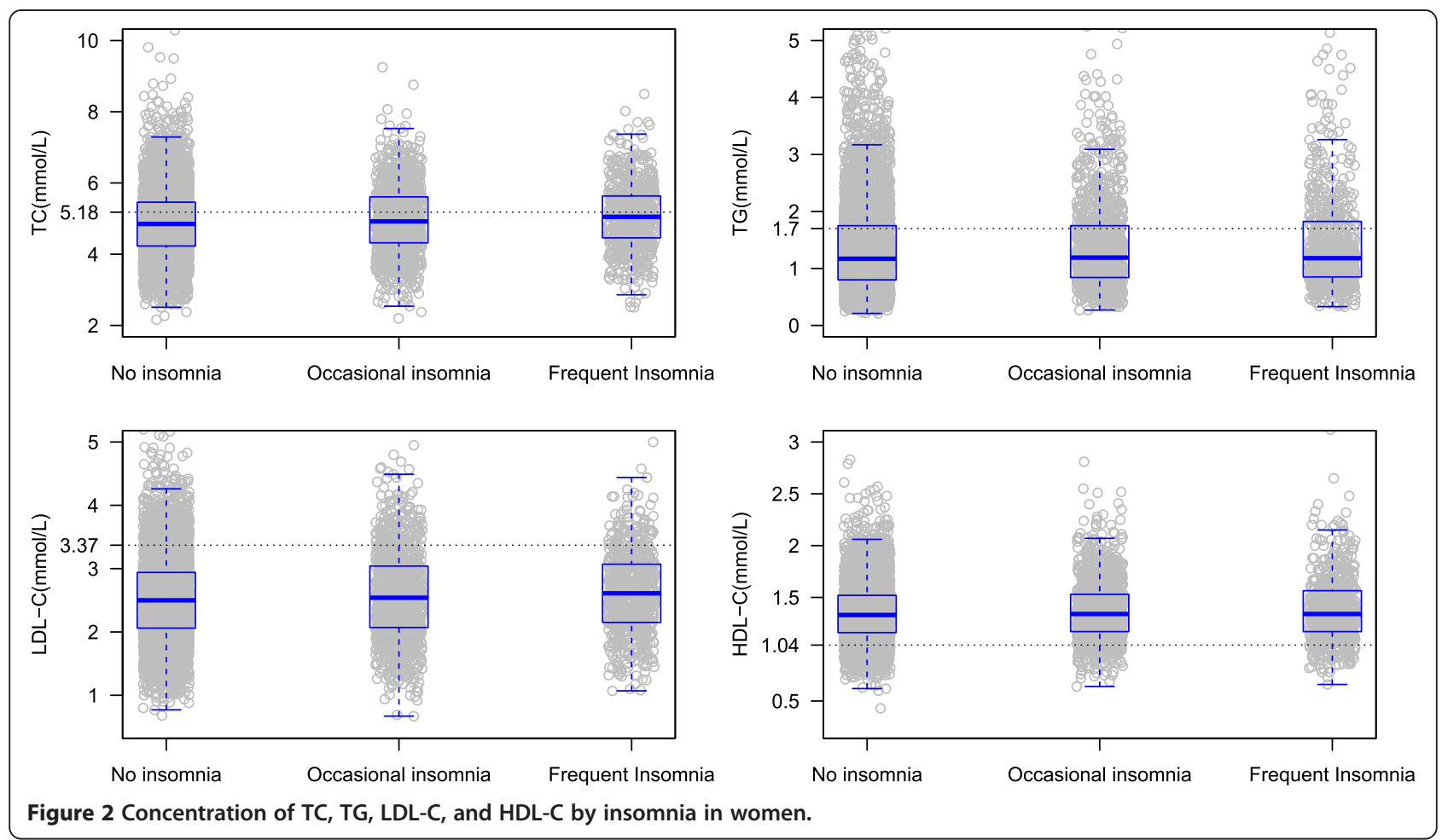

1.60) for men and $1.00(0.86,1.14)$ and $1.23(1.03,1.47)$ for women in the multivariable adjusted models. The ORs were not substantially different in the other models.

\section{Discussion}

Previous studies regarding sleep disorder or serum lipid were well documented in literature. Nevertheless, to our knowledge, few researches were conducted to explore insomnia and dyslipidemia simultaneously or examine the association between them, especially in the Chinese population [25]. In the present study, we investigated the association between self-reported insomnia and dyslipidemia and serum lipid markers in a communitybased sample and found that frequent insomnia was

Table 2 Prevalence of dyslipidemia among subjects with different insomnia status [n(\%)]

\begin{tabular}{|c|c|c|c|c|c|c|}
\hline & & Abnormal TC & Abnormal TG & Abnormal LDL-C & Abnormal HDL-C & Dyslipidemia \\
\hline \multicolumn{7}{|l|}{ All } \\
\hline & No Insomnia & $2457(32.2)$ & $2100(27.5)$ & 739(9.7) & $1253(16.4)$ & $4008(52.5)$ \\
\hline & Occasional Insomnia & $558(36.1)$ & $431(27.9)$ & 173(11.2) & 214(13.9) & $844(54.6)$ \\
\hline & Frequent Insomnia & $361(41.2)$ & $238(27.1)$ & 105(12.0) & $128(14.6)$ & $522(59.5)$ \\
\hline$P^{*}$ & & $<0.0001$ & 0.9525 & 0.0095 & 0.0203 & $<0.0001$ \\
\hline \multicolumn{7}{|c|}{ Men } \\
\hline & No Insomnia & $845(27.6)$ & $885(28.9)$ & $242(7.9)$ & $725(23.7)$ & 1632(53.3) \\
\hline & Occasional Insomnia & $110(27.5)$ & 125(31.3) & $28(7.0)$ & $98(24.5)$ & $217(54.3)$ \\
\hline & Frequent Insomnia & $67(30.2)$ & $57(25.7)$ & $21(9.5)$ & $52(23.4)$ & $121(54.5)$ \\
\hline$P^{*}$ & & 0.5001 & 0.7232 & 0.7058 & 0.9069 & 0.6313 \\
\hline \multicolumn{7}{|c|}{ Women } \\
\hline & No Insomnia & $1612(35.3)$ & 1215(26.6) & 497(10.9) & $528(11.6)$ & $2376(52.0)$ \\
\hline & Occasional Insomnia & 448(39.1) & $306(26.7)$ & $145(12.7)$ & 116(10.1) & $627(54.8)$ \\
\hline & Frequent Insomnia & 294(44.9) & $181(27.6)$ & $84(12.8)$ & 76(11.6) & $401(61.2)$ \\
\hline$P^{*}$ & & $<0.0001$ & 0.6173 & 0.0501 & 0.5673 & $<0.0001$ \\
\hline
\end{tabular}

${ }^{*}$ Cochran-Armitage trend test. 
Table 3 Odds ratios and $95 \%$ confidence intervals between insomnia and TC, TG, LDL-C, and HDL-C

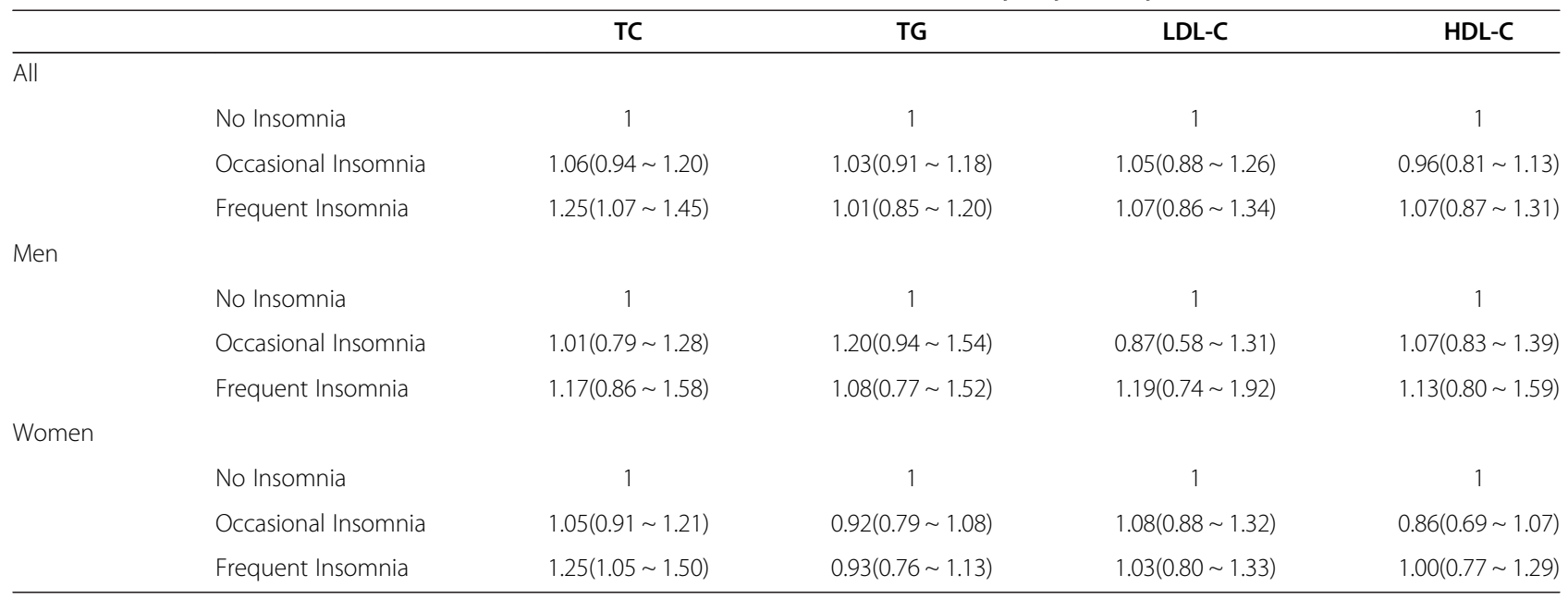

TC, total cholesterol; TG, triglyceride; LDL-C, low density lipoprotein cholesterol; HDL-C, high density lipoprotein cholesterol.

Models for all: insomnia, age, education, obesity, BMI, physical activity, current smoking, current drinking, work stress, hypertension, and diabetes (plus gender when men and women analyzed together).

related to higher prevalence of dyslipidemia and TC compared with those who reported no insomnia in women. This association was not statistical significant in men and independent of age, BMI, education, physical activity, current smoking, current drinking, obesity, diabetes, and hypertension.

Insomnia is usually accompanied with short sleep duration. Recent study suggested that short sleep duration was associated with higher risks of hypercholesterolemia in the adults of US [11] and Japan [12]. Likewise, reduced sleep duration was found to be related to dyslipidemia in other studies [26,27]. However, some other studies reported different results which stated difficulty falling asleep was not associated with TG or HDL-C
[28]. Different study design, source population, and socioeconomic status might explain the discrepancy. Previous studies also implied that women were more prone to suffer from insomnia than men $[29,30]$, and gender also played a key role in cardiovascular diseases and mortality [31]. Therefore, a gender inequality of the association between self-reported insomnia and dyslipidemia would be plausible. In our study, more women had insomnia than men $(P<0.0001)$. On the contrary, the prevalence of dyslipidemia in women was almost identical to that in men $(P=0.99)$. Thus, we hypothesized that the association between insomnia and dyslipidemia might be affected by gender. Our results did not contradict this hypothesis. The association of self-reported

Table 4 Odds ratios and $95 \%$ confidence intervals between insomnia and dyslipidemia

\begin{tabular}{|c|c|c|c|c|}
\hline & & Model 1 & Model 2 & Model 3 \\
\hline \multicolumn{5}{|l|}{ All } \\
\hline & No Insomnia & 1 & 1 & 1 \\
\hline & Occasional Insomnia & $1.08(0.98 \sim 1.21)$ & $1.01(0.91 \sim 1.14)$ & $1.06(0.94 \sim 1.19)$ \\
\hline & Frequent Insomnia & $1.33(1.15 \sim 1.53)$ & $1.17(1.01 \sim 1.35)$ & $1.28(1.10 \sim 1.49)$ \\
\hline \multicolumn{5}{|c|}{ Men } \\
\hline & No Insomnia & 1 & 1 & 1 \\
\hline & Occasional Insomnia & $1.04(0.84 \sim 1.28)$ & $1.04(0.84 \sim 1.28)$ & $1.08(0.87 \sim 1.36)$ \\
\hline & Frequent Insomnia & $1.05(0.80 \sim 1.38)$ & $1.05(0.80 \sim 1.39)$ & $1.21(0.90 \sim 1.63)$ \\
\hline \multicolumn{5}{|c|}{ Women } \\
\hline & No Insomnia & 1 & 1 & 1 \\
\hline & Occasional Insomnia & $1.12(0.98 \sim 1.27)$ & $0.96(0.84 \sim 1.10)$ & $1.00(0.87 \sim 1.15)$ \\
\hline & Frequent Insomnia & $1.46(1.23 \sim 1.72)$ & $1.15(0.97 \sim 1.38)$ & $1.25(1.04 \sim 1.50)$ \\
\hline
\end{tabular}


insomnia and dyslipidemia was significantly different between men and women. Insomnia might pose more risk to dyslipidemia in women. The reasons of the observed gender difference in the association between insomnia and dyslipidemia remains unclear, but recent research results were still able to provide suggestive clues. Firstly, it was reported that women were more prone to suffer psychiatric disorders and lacking coping ability [32,33], both of which were related to sleep disorders. In addition to that, sex hormone was also found to be of paramount significance to exhibit influence on gender specific sleep habits [34]. Last but not least, lower socioeconomic status for women might partially explain the discrepancy [19]. In the present study, after adjusting for several well established risk factors for dyslipidemia, the association of insomnia and dyslipidemia was still significant in women. This indicated that other biological mechanisms might play a role in the gender differences. This research question should be addressed in future large longitudinal cohort studies.

In the present study, we also analyzed the association between insomnia and the individual components of serum lipid. We found that insomnia was associated with TC in women other than men, and we did not find a significant association between insomnia and TG, LDL-C, or HDL-C. This implied that the association between insomnia and dyslipidemia might be mainly due to the association of insomnia and TC. However, studies which directly explore the association of insomnia and serum lipid are scarce. Most of them focused on sleep duration and metabolic markers including serum lipid.

Several potential mechanisms might be proposed to explain the link of insomnia and dyslipidemia. Firstly, insomnia usually contributed to reduced sleep duration. People with reduced sleep duration tended to show a preference of high energy-density fatty food [35] and have a higher BMI via reducing leptin and elevating ghrelin [36,37]. Higher BMI and intake of fat rich food were able to increase the risk of dyslipidemia [38]. In our study, the association of insomnia and dyslipidemia were still significant after adjusting BMI and obesity. This indicates that the observed association was independent of BMI or obesity. The link should be further explained by other possible mechanisms. Secondly, although the causes and physiology of insomnia have not been completely understood, it is generally considered as one kind of hyperarousal disorder related to increased activity of hypothalamicpituitary-adrenal-axis [13]. During this process, cortisol [39] will be secreted excessively. Elevated cortisol is able to induce higher cholesterol [40]. Finally, Insomnia and dyslipidemia share some common risk factors, such as smoking [41,42] and alcohol consumption [43]. Thus, the abnormalities of the neuroendocrine system and unhealthy lifestyle may present a biological plausibility between insomnia and abnormal lipid status. In addition to the aforementioned statements, depression or other psychiatric disorder might act as mediators in the association between insomnia and dyslipidemia. A metaanalysis using longitudinal epidemiological studies found that non-depressed individuals with insomnia had a twofold risk to develop depression compared with those without sleep difficulties [44]. Insomnia was also closely relatred to other psychiatric disorder [45]. Patients with major depressive or psychiatric disorders had a worse lipid profile in the Netherlands Study of Depression and Anxiety [46] as well as in a Chinese cohort [47]. In the present study, depression and psychiatric disorders were not measured, and further analysis regarding the mediating effects was unavailable. However, the mediation effects of depression and psychiatric disorders deserve detailed examination in future studies.

Our results have meaningful implications for both public health and clinical practice professionals. Since insomnia is a modifiable risk factor for chronic diseases including abnormal serum lipid profile, treating insomnia might have protective effects on lowering TC levels as well as deceasing dyslipidemia prevalence. However, more longitudinal studies and clinical trials are warranted to examine the causal relationship between insomnia and dyslipidemia or whether treating insomnia with medicine has beneficial effects on patients' lipid levels.

This study has some limitations. The present data was collected using a cross-sectional design, we cannot make causal inferences regarding whether insomnia precedes or causes dyslipidemia. Furthermore, more women than men participated in the survey. Women paid much more attention to their health, which could result in an overestimation of the prevalence of insomnia in the source population. But this would have little effect on the reported association of insomnia and dyslipidemia after stratifying analysis by gender. Finally, insomnia was collected in a single question rather than multiple questions proposed by other studies [13], so we cannot examine the association between other insomnia symptoms and dyslipidemia in the present study.

\section{Conclusions}

In conclusion, self-reported insomnia was associated with higher prevalence of dyslipidemia and TC in this large Chinese women sample. Future longitudinal studies should be conducted to further explore the causal relationship and to clarify the biological mechanisms between them.

\section{Abbreviations}

TC: Total cholesterol; TG: Triglyceride; LDL-C: Low density lipoprotein cholesterol; HDL-C: High density lipoprotein cholesterol; BMI: Body mass 
index; SBP: Systolic blood pressure; DBP: Diastolic blood pressure; OR: Odds ratio; Cl: Confidence interval.

\section{Competing interests}

The authors declare that they have no competing interests.

\section{Authors' contributions}

Conceived the study: JY DH; collected the materials: YZ FZ JW YS RD; conducted the analysis: YZ FZ; Wrote the manuscript: YZ FZ LL; Revised the manuscript: YZ FZ LL JW YS RD JY DH; approved the manuscript: JY DH. All authors read and approved the final manuscript.

\section{Acknowledgements}

We thank both the residents of Beijing for their participation in the survey and local medical staff for their cooperation and support. This work was supported by a Research Funding (No. D0906002040191) from Beijing Municipal Science and Technology Commission, China.

\section{Author details}

${ }^{1}$ Key Laboratory of Public Health Safety, Ministry of Education, School of Public Health, Fudan University, Shanghai, P. R. China. ${ }^{2}$ Institute of Clinical Epidemiology, School of Public Health, Fudan University, Shanghai, P. R. China. ${ }^{3}$ Department of Chronic Disease Prevention, Minhang Center for Disease Control and Prevention, Shanghai, P. R. China. ${ }^{4}$ Department of Dermatology, Linyi People's Hospital, Linyi, P. R. China. ${ }^{5}$ Department of Preventive Medicine, School of Medicine, Yangzhou University, Yangzhou, P. R. China. ${ }^{6}$ Heart Center, Peking University People's Hospital, Peking University, Beijing, P. R. China.

Received: 7 June 2014 Accepted: 3 October 2014

Published: 8 October 2014

\section{References}

1. Shao $B$, Heinecke JW: $H D L$, lipid peroxidation, and atherosclerosis. J Lipid Res 2009, 50(4):599-601.

2. Voight BF, Peloso GM, Orho-Melander M, Frikke-Schmidt R, Barbalic M Jensen MK, Hindy G, Hólm H, Ding EL, Johnson T, Schunkert H, Samani NJ, Clarke R, Hopewell JC, Thompson JF, Li M, Thorleifsson G, Newton-Cheh C, Musunuru K, Pirruccello JP, Saleheen D, Chen L, Stewart A, Schillert A, Thorsteinsdottir U, Thorgeirsson G, Anand S, Engert JC, Morgan T, Spertus J, et al: Plasma HDL cholesterol and risk of myocardial infarction: a mendelian randomisation study. Lancet 2012, 380(9841):572-580.

3. Emerging Risk Factors Collaboration, Di Angelantonio E, Gao P, Pennells L, Kaptoge S, Caslake M, Thompson A, Butterworth AS, Sarwar N, Wormser D, Saleheen D, Ballantyne CM, Psaty BM, Sundström J, Ridker PM, Nagel D, Gillum RF, Ford I, Ducimetiere P, Kiechl S, Koenig W, Dullaart RP, Assmann G, D'Agostino RB Sr, Dagenais GR, Cooper JA, Kromhout D, Onat A, Tipping RW, Gómez-de-la-Cámara A, et al: Lipid-related markers and cardiovascular disease prediction. JAMA 2012, 307(23):2499-2506.

4. Li YH, Li Y, Davis CE, Chen Z, Tao S, Folsom AR, Bachorik P, Stamler J, Abernathy JR: Serum cholesterol changes from 1983-1984 to 1993-1994 in the People's Republic of China. Nutr Metab Cardiovasc Dis 2002, 12(3):118-126

5. He J, Gu D, Reynolds K, Wu X, Muntner P, Zhao J, Chen J, Liu D, Mo J, Whelton PK: Serum total and lipoprotein cholesterol levels and awareness, treatment, and control of hypercholesterolemia in China. Circulation 2004, 110(4):405-411.

6. Scheidt-Nave C, Du Y, Knopf H, Schienkiewitz A, Ziese T, Nowossadeck E, Gosswald A, Busch MA: Prevalence of dyslipidemia among adults in Germany: results of the German Health Interview and Examination Survey for Adults (DEGS 1). Bundesgesundheitsblatt Gesundheitsforschung Gesundheitsschutz 2013, 56(5-6):661-667.

7. Toth PP, Potter D, Ming EE: Prevalence of lipid abnormalities in the United States: the National Health and Nutrition Examination Survey 2003-2006. J Clin Lipidol 2012, 6(4):325-330.

8. Tamura U, Tanaka T, Okamura T, Kadowaki T, Yamato H, Tanaka H, Nakamura M, Okayama A, Ueshima H, Yamagata Z: Changes in weight, cardiovascular risk factors and estimated risk of coronary heart disease following smoking cessation in Japanese male workers: HIPOP-OHP study. J Atheroscler Thromb 2010, 17(1):12-20.
9. Kuzuya M, Ando F, Iguchi A, Shimokata H: Age-specific change of prevalence of metabolic syndrome: longitudinal observation of large Japanese cohort. Atherosclerosis 2007, 191(2):305-312.

10. Toyama Y, Chin K, Chihara Y, Takegami M, Takahashi K, Sumi K, Nakamura T, Nakayama-Ashida Y, Minami I, Horita S, Oka Y, Wakamura T, Fukuhara S, Mishima M, Kadotani H: Association between sleep apnea, sleep duration, and serum lipid profile in an urban, male, working population in Japan. Chest 2013, 143(3):720-728.

11. Gangwisch JE, Malaspina D, Babiss LA, Opler MG, Posner K, Shen S, Turner $J B$, Zammit GK, Ginsberg HN: Short sleep duration as a risk factor for hypercholesterolemia: analyses of the National Longitudinal Study of Adolescent Health. Sleep 2010, 33(7):956-961.

12. Kaneita Y, Uchiyama M, Yoshiike N, Ohida T: Associations of usual sleep duration with serum lipid and lipoprotein levels. Sleep 2008, 31(5):645-652.

13. Roth T: Insomnia: definition, prevalence, etiology, and consequences. J Clin Sleep Med 2007, 3(5 Suppl):S7-S10.

14. Leger D, Morin CM, Uchiyama M, Hakimi Z, Cure S, Walsh JK: Chronic insomnia, quality-of-life, and utility scores: comparison with good sleepers in a cross-sectional international survey. Sleep Med 2012, 13(1):43-51.

15. Sarsour K, Morin CM, Foley K, Kalsekar A, Walsh JK: Association of insomnia severity and comorbid medical and psychiatric disorders in a health plan-based sample: Insomnia severity and comorbidities. Sleep Med 2010, 11(1):69-74.

16. Chiang YY, Tsai PY, Chen PC, Yang MH, Li CY, Sung FC, Chen KB: Sleep disorders and traffic accidents. Epidemiology 2012, 23(4):643-644.

17. Laugsand LE, Vatten $L$, Platou $C$, Janszky I: Insomnia and the risk of acute myocardial infarction: a population study. Circulation 2011, 124(19):2073-2081.

18. Laugsand LE, Strand LB, Platou C, Vatten LJ, Janszky I: Insomnia and the risk of incident heart failure: a population study. Eur Heart J 2014, 35(21):1382-93.

19. Zhan Y, Yu J, Chen R, Gao J, Ding R, Fu Y, Zhang L, Hu D: Socioeconomic status and metabolic syndrome in the general population of China: a cross-sectional study. BMC Public Health 2012, 12:921.

20. AmericanDiabetesAssociation: Diagnosis and classification of diabetes mellitus. Diabetes Care 2014, 37(Suppl 1):S81-S90.

21. James PA, Oparil S, Carter BL, Cushman WC, Dennison-Himmelfarb C, Handler J, Lackland DT, LeFevre ML, MacKenzie TD, Ogedegbe O, Smith SC Jr, Svetkey LP, Taler SJ, Townsend RR, Wright JT Jr, Narva AS, Ortiz E: 2014 evidence-based guideline for the management of high blood pressure in adults: report from the panel members appointed to the Eighth Joint National Committee (JNC 8). JAMA 2014, 311(5):507-520.

22. Joint Committee for Developing Chinese guidelines on Prevention and Treatment of Dyslipidemia in Adults: Chinese guidelines on prevention and treatment of dyslipidemia in adults. Zhonghua Xin Xue Guan Bing Za Zhi 2007, 35(5):390-419.

23. Armitage P: Tests for linear trends in proportions and frequencies. Biometrics 1955, 11(3):375-386.

24. R Development Core Team: R: A Language and Enviroment for Statistical Programming. Vienna, Austria: R Foundation for Statistical Computing; 2012.

25. Chien KL, Chen PC, Hsu HC, Su TC, Sung FC, Chen MF, Lee YT: Habitual sleep duration and insomnia and the risk of cardiovascular events and all-cause death: report from a community-based cohort. Sleep 2010, 33(2):177-184.

26. Kong AP, Wing YK, Choi KC, Li AM, Ko GT, Ma RC, Tong PC, Ho CS, Chan MH, Ng $\mathrm{MH}$, Lau J, Chan JC: Associations of sleep duration with obesity and serum lipid profile in children and adolescents. Sleep Med 2011, 12(7):659-665.

27. Zhan $Y$, Chen $R$, Yu J: Sleep duration and abnormal serum lipids: the China Health and Nutrition Survey. Sleep Med 2014, 15(7):833-839.

28. Troxel WM, Buysse DJ, Matthews KA, Kip KE, Strollo PJ, Hall M, Drumheller O, Reis SE: Sleep symptoms predict the development of the metabolic syndrome. Sleep 2010, 33(12):1633-1640.

29. Zhang B, Wing YK: Sex differences in insomnia: a meta-analysis. Sleep 2006, 29(1):85-93.

30. Li RH, Wing YK, Ho SC, Fong SY: Gender differences in insomnia-a study in the Hong Kong Chinese population. J Psychosom Res 2002, 53(1):601-609.

31. Barrett-Connor E: Sex differences in coronary heart disease. Why are women so superior? The 1995 Ancel Keys Lecture. Circulation 1997, 95(1):252-264 
32. Angst J, Gamma A, Gastpar M, Lepine JP, Mendlewicz J, Tylee A: Gender differences in depression. Epidemiological findings from the European DEPRES I and II studies. Eur Arch Psychiatry Clin Neurosci 2002, 252(5):201-209.

33. Kelly MM, Tyrka AR, Price LH, Carpenter LL: Sex differences in the use of coping strategies: predictors of anxiety and depressive symptoms. Depress Anxiety 2008, 25(10):839-846.

34. Mong JA, Baker FC, Mahoney MM, Paul KN, Schwartz MD, Semba K, Silver R: Sleep, rhythms, and the endocrine brain: influence of sex and gonadal hormones. J Neurosci 2011, 31(45):16107-16116.

35. Santana AA, Pimentel GD, Romualdo M, Oyama LM, Santos RV, Pinho RA, de Souza CT, Rodrigues B, Caperuto EC, Lira FS: Sleep duration in elderly obese patients correlated negatively with intake fatty. Lipids Health Dis 2012, 11:99.

36. Taheri S, Lin L, Austin D, Young T, Mignot E: Short sleep duration is associated with reduced leptin, elevated ghrelin, and increased body mass index. Plos Med 2004, 1(3):210-217.

37. Patel SR, Hu FB: Short sleep duration and weight gain: a systematic review. Obesity 2008, 16(3):643-653.

38. Brown CD, Higgins M, Donato KA, Rohde FC, Garrison R, Obarzanek E, Ernst ND, Horan M: Body mass index and the prevalence of hypertension and dyslipidemia. Obes Res 2000, 8(9):605-619.

39. Vgontzas AN, Bixler EO, Lin HM, Prolo P, Mastorakos G, Vela-Bueno A, Kales A, Chrousos GP: Chronic insomnia is associated with nyctohemeral activation of the hypothalamic-pituitary-adrenal axis: clinical implications. J Clin Endocrinol Metab 2001, 86(8):3787-3794.

40. Fraser R, Ingram MC, Anderson NH, Morrison C, Davies E, Connell JM: Cortisol effects on body mass, blood pressure, and cholesterol in the general population. Hypertension 1999, 33(6):1364-1368.

41. Brook DW, Rubenstone E, Zhang CS, Brook JS: Trajectories of cigarette smoking in adulthood predict insomnia among women in late mid-life. Sleep Med 2012, 13(9):1130-1137.

42. Tan XJ, Jiao GP, Ren YJ, Gao XR, Ding Y, Wang XR, Xu H: Relationship between smoking and dyslipidemia in western Chinese elderly males. J Clin Lab Anal 2008, 22(3):159-163.

43. Wong WS, Fielding R: Prevalence of insomnia among Chinese adults in Hong Kong: a population-based study. J Sleep Res 2011, 20(1 Pt 1):117-126.

44. Baglioni C, Battagliese G, Feige B, Spiegelhalder K, Nissen C, Voderholzer U, Lombardo C, Riemann D: Insomnia as a predictor of depression: a metaanalytic evaluation of longitudinal epidemiological studies. J Affect Disord 2011, 135(1-3):10-19.

45. Riemann D: Insomnia and comorbid psychiatric disorders. Sleep Med 2007, 8(Suppl 4):S15-S20.

46. van Reedt Dortland AK, Giltay EJ, van Veen T, van Pelt J, Zitman FG, Penninx BW: Associations between serum lipids and major depressive disorder: results from the Netherlands Study of Depression and Anxiety (NESDA). J Clin Psychiatry 2010, 71(6):729-736

47. Liang Y, Yan Z, Cai C, Jiang H, Song A, Qiu C: Association between lipid profile and depressive symptoms among Chinese older people: mediation by cardiovascular diseases? Int J Behav Med 2014, 21(4):590-596.

doi:10.1186/1471-2458-14-1050

Cite this article as: Zhan et al:: Prevalence of dyslipidemia and its association with insomnia in a community based population in China. BMC Public Health 2014 14:1050

\section{Submit your next manuscript to BioMed Central and take full advantage of:}

- Convenient online submission

- Thorough peer review

- No space constraints or color figure charges

- Immediate publication on acceptance

- Inclusion in PubMed, CAS, Scopus and Google Scholar

- Research which is freely available for redistribution

Submit your manuscript at www.biomedcentral.com/submit 